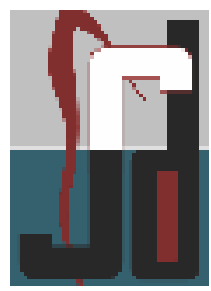

CASE SERIES

\title{
Squamous Cell Carcinoma of Supraglottic
}

S.P. Indra Kumar' ${ }^{1}$, Gayathri Priyadharshini², Priyadharshini ${ }^{3}$, Venkat Narayanan ${ }^{4}$

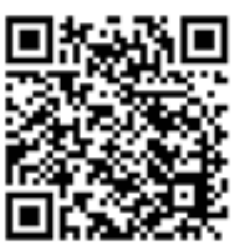

ABSTRACT : Laryngeal carcinoma, are mostly squamous cell carcinomas, reflecting their origin from the skin of the larynx. Most laryngeal cancers originate in the glottis. Supraglottic cancers are less common and subglottic tumours are least frequent. Supraglottic cancer is a disease in which malignant (cancer) cells form in the tissues of the larynx. Use of tobacco products and drinking too much alcohol can affect the risk of laryngeal cancer. The complaint of the patient includes a sore throat and ear pain. CT scan of throat and neck are used to help detect, diagnose, and stage laryngeal cancer. Management of the head and neck cancer patient most often will include radiation therapy. The oral complications of head and neck Radiation therapy result from radiation injury to the salivary glands, oral mucosa and taste buds, oral musculature, alveolar bone, and skin. The oral complications of therapy for head and neck cancer can significantly impair quality of life. The oral health care team serves a vital role in the prevention and management of short- and long-term oral complications of cancer treatment.Here I present two cases of supraglottic carcinomawhounderwentoral health care before radiation therapy.

Keywords : Suproglottic larynx, Squamous Cell Carcinoma of head and neck

\section{INTRODUCTION}

Laryngeal cancer represents one of the most common head and neck malignancies, accounting approximately for $20 \%$ of all cases. The vast majority of tumors are squamous cell carcinoma. Up to $40 \%$ of patients present with advanced disease. Due to the important physiologic functions of the larynx, advanced laryngeal lesions are associated with significant morbidity and mortality for the patient and increased financial costs for society. ${ }^{1}$ Laryngeal cancer is a disease that usually presents with hoarseness. It is most common in older people and those of lower socio-economic classes. Understanding the warning signs and symptoms can help in making an early referral to the ear, nose and throat. ${ }^{2}$ It is a relatively common cancer in men, but rarer in women. ${ }^{3}$ Early laryngeal cancer is treated by operation, including transoral laser excision or radiotherapy. Advanced laryngeal cancer has been treated with mutilating operations, such as a total laryngectomy. ${ }^{4}$ However, a laryngeal preserving approach, which can improve the quality of life, has recently been tried with advanced laryngeal cancer. ${ }^{4}$ Studies demonstrate that coffee consumption would increase the laryngeal cancer risk, while tea intake ${ }^{5}$ was not associated with risk of laryngeal carcinoma. ${ }^{5,6}$ These cancers will manifest with oral signs and symptoms. The purpose of this case report is to create awareness among the clinician that, examination of the oral cavity and dentition is must for cancer patients. $7,{ }^{8}$ Management forsuch patients includesevaluation of dental history, oral hygiene maintenance, the emotional state of the patient, socio-economic status of the patient, future quality of life, the medical and/or life prognosis of the patient.Primary care dental teams will be involved in the long-term management of oral care for head and cancer patients. ${ }^{9} \mathrm{~A}$ broad understanding of the management of head and neck cancer, consequences of treatment and the need for good communication is key to good quality patient care. ${ }^{10}$

\section{Case 1:}

A 52-year-old man was diagnosed as a case of carcinoma of supraglottic. The patient was apparently normal before 9 months, then he developed difficulty in swallowing and difficulty in opening the mouth. swelling in the neck is initially small and gradually increased in size. Histopathology report of primary site was diagnosed as squamous cell carcinoma, The patient was planned for radical chemo-radiation after complete clinical and investigative workup. Routine oral examination was performed and followed by oral 
prophylaxis and extraction and then patient send for radiation (figure 1-3).

\section{Case 2:}

A 55year old male reported to ENT OPD with complaint of voice change and c/o of throat pain for past 4 months. On further investigation it was aulceroproliferative growth in larynx of epiglottic and extended into areepiglottic fold. histopathology report shows ulceration of lining epithelium and hemorrhage. The subepithelium shows invasion by atypical squamous cells. The CT scan report shows supraglottic laryngeal growth with probable involment of base of tongue. Routine oral examination was performed and followed by oral prophylaxis and extraction and then patient send for radiation.

\section{DISCUSSION}

The dentist caring for a head and neck cancer patient should have clearly defined goals of dental managementduring the three phases of treatment:

\section{Pretreatment goals}

a. Eliminate potential sources of infection;

b. Counsel patient about short- and long-term complicationsof cancer therapy;

c. Provide preventive care.

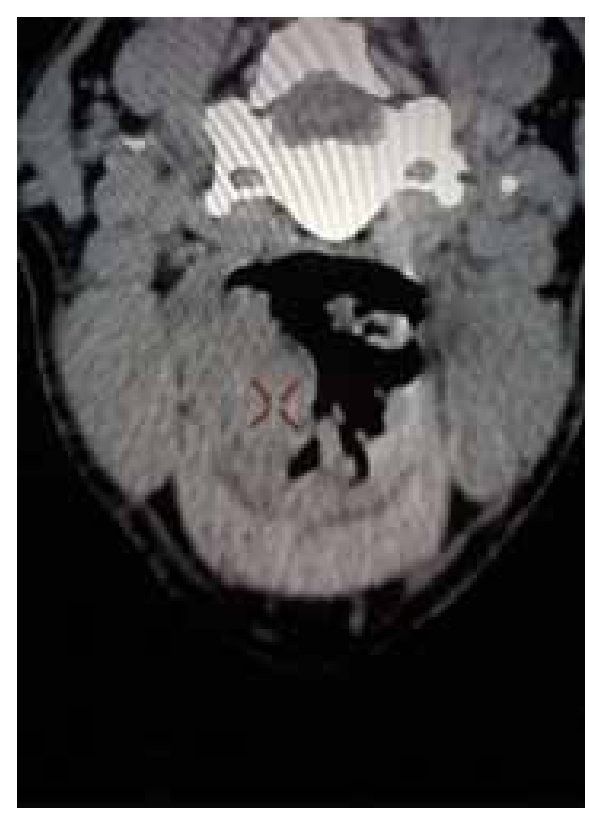

Figure 1 : CT Scan Showing Lobulated Soft Tissue Density Lesion involving Epiglottic fold.

\section{Goals during cancer therapy}

a. Provide supportive care for oral mucositis;

b. Provide treatment of oral candidiasis;

c. Manage xerostomia;

d. Prevent trismus.

\section{Long-term, post-treatment goals}

a. Manage xerostomia;

b. Prevent and minimize trismus;

c. Prevent and treat dental caries;

d. Prevent postradiation osteonecrosis (ORN);

e. Detect tumor recurrence. ${ }^{11,12}$

The dentist should encourage the patient to adopt a non-cariogenic diet. Tooth extraction should be performed14 days before radiation or chemotherapy starts. After RT, allow at least three months of healing time to elapse before providing prostheses in edentulous patients. There appears to be little evidence to support a longer delay to definitive prosthetic care.During preRT extractions, the dentist should aggressively remove sharp pieces of bone to avoid alveoloplasty.

\section{CONCLUSION:}

The dental care provider can help prepare the patient prior to therapy by treating any active or potentialdental infection, providing patient education, and supportive care during treatment. The dental treatment and oral

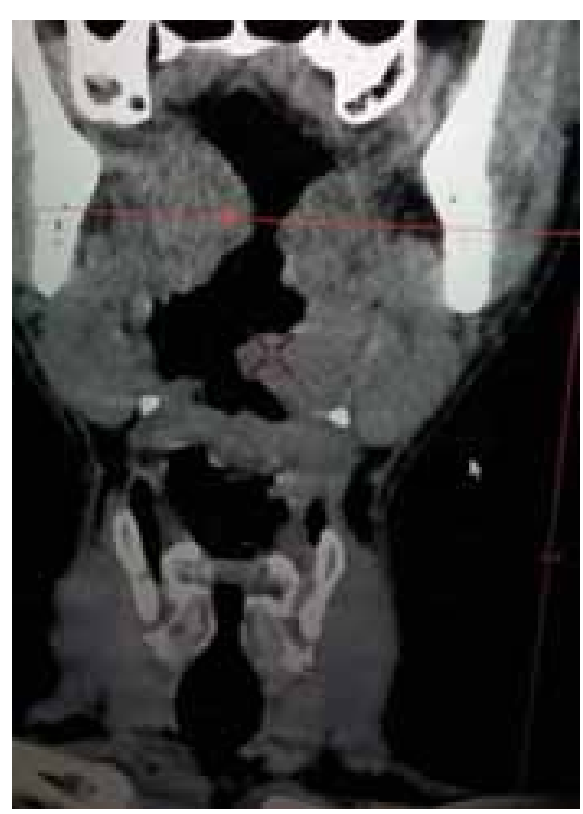

Figure 2 : CT Scan Showing Lobulated Soft Tissue Density Lesion involving Aryepiglottic Fold 


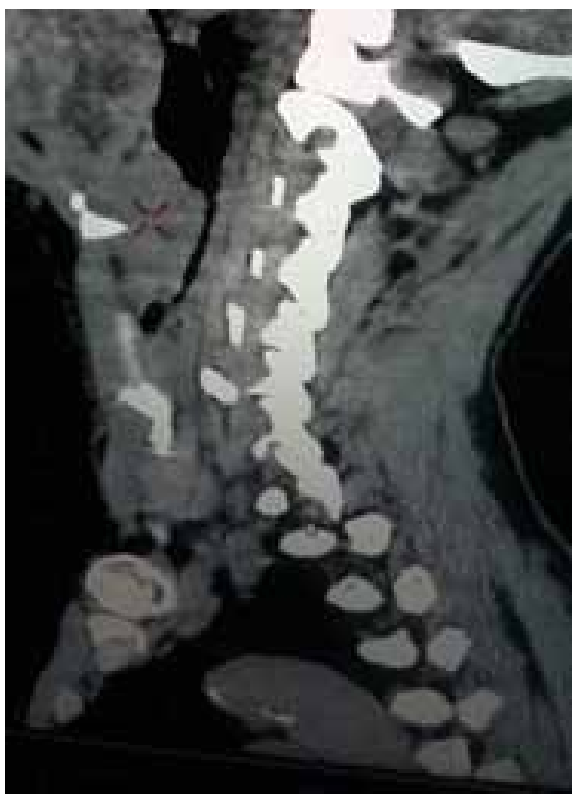

\section{Figure 3: CT Scan Showing Lobulated Soft Tissue Density Lesion involving Valleculae And Base of Tongue.}

management of patients with head and neck cancer should include an oral evaluation including periodontal examination before the patient begins cancer treatment. This evaluation will help to prevent oral complications associated with radiation and chemotherapy, and systemic sequelae of oral infection.

\section{REFERENCES:}

1. Karatzanis et al. Journal of Otolaryngology - Head and Neck Surgery. 2014; 43:4.

2. Timothy C. Biggs. Hoarseness Innovait: The RCGP Journal for Associates in Training. 2012; 5: 226-231.

3. M.S. Cattaruzza P. MaisonneuveP. Boyle. Epidemiology of laryngeal cancer. 2001; 32(5): 293-305.

4. Youn Sang Shim.Recent Advances in Management of Laryngeal Cancer.Cancer Research and Treatment 2004;36(1):13-18.

5. Jiangbo Chen, Shuo Long.Tea and Coffee Consumption and Risk of Laryngeal Cancer: A Systematic Review MetaAnalysis.2014;9(12): 1-12.
6. K. Gilbert, R.W. Dalley, N. Maronian, Y.Anzai. Staging of Laryngeal Cancer Using 64-Channel Multidetector Row CT: Comparison of Standard Neck CT with Dedicated BreathManeuver Laryngeal CT. AJNR 2010; 31: 251-256

7. Patrick Sheahan Rambam. Management of Advanced Laryngeal Cancer.Maimonides Med J 2014; 5(2): 5-9

8. Gregory S. Weinstein. Surgical Approach to Organ Preservation in the Treatment of Cancer of the Larynx.Oncology Journal, Head \& Neck Cancer. 2001;1:1-4.

9. Erkan Karatas, Elif Baysal, Cengiz Durucu , Tekin Bağlam, Yildırım Ahmet,et al. Evaluation of the treatment results of laryngeal carcinoma: our experience over 10 years J Med Sci 2012; 42 (2): 1394-1399.

10. Haigentz M Jr, Silver CE, Hartl DM, Takes RP, Rodrigo JP et al. Expert Opin Pharmacother. Chemotherapy regimens and treatment protocols for laryngeal cancer2010;11(8):1305-16.

11. Zlotolow IM. Dental Oncology and Maxillofacial Prosthetics. Philadelphia:Lippincott Raven; 1999.

12. Epstein JB, van der Meij EH, Emerton SM, Le ND, StevensonMoore P. Compliance with fluoride gel use in irradiated patients. Spec Care Dentist1995;15:218-22. 


\section{Address of Correspondence}

Dr. S.P. Indra Kumar MDS,

Assistant Professor,

Department of Dentistry,

AarupadaiVeedu Medical College \& Hospital,

Puducherry

Email id : kumarjeeth@yahoo.com

Phone no : 8870109255

\section{Authors:}

${ }^{1}$ Assistant Professor, Department of Dentistry, Aarupadai Veedu Medical College \& Hospital, Pondicherry.

${ }^{2}$ Senior Lecturer, Department of Periodontology, Indira Gandhi Institute of Dental Sciences, Puducherry.

${ }^{3}$ Assistant Professor, Department of ENT, AarupadaiVeedu Medical College \& Hospital, Puducherry.

${ }^{4}$ Associate Professor, Department of Dentistry, Aarupadai Veedu Medical College \& Hospital, Puducherry.

\section{How to cite this article :}

S.P. Indra Kumar, Gayathri Priyadharshini, Priyadharshini, Venkat Narayanan. Squamous Cell Carcinoma of Supraglottic. Journal of Scientific Dentistry, 2016;6(1):20-23

Source of Support : Nil, Conflicts of Interest : None declared 